\title{
A Decade of Global mRNA and miRNA Profiling of HPV-Positive Cell Lines and Clinical Specimens
}

\author{
Bogumil Kaczkowski ${ }^{1}$, Marya Morevati ${ }^{2}$, Maria Rossing ${ }^{3,4}$, Finn Cilius ${ }^{3}$ and Bodil Norrild ${ }^{*}, 2$
}

${ }^{1}$ The Bioinformatics Centre, Department of Biology and Biomedical Research and Innovation Centre, University of Copenhagen, Ole Maaloes Vej 5, DK-2200 Copenhagen, Denmark

${ }^{2}$ Institute of Cellular and Molecular Medicine, DNA Tumour Virus Laboratory, University of Copenhagen, Panum Institute, Blegdamsvej 3, DK-2200 Copenhagen, Denmark

${ }^{3}$ Centre for Genomic Medicine, Copenhagen University Hospital, Blegdamsvej 9, DK-2100 Copenhagen, Denmark

${ }^{4}$ Department of Clinical Biochemistry, Copenhagen University Hospital, Blegdamsvej 5, DK-2100 Copenhagen, Denmark

\begin{abstract}
For more than a decade, global gene expression profiling has been extensively used to elucidate the biology of human papillomaviruses (HPV) and their role in cervical- and head-and-neck cancers. Since 2008, the expression profiling of miRNAs has been reported in multiple HPV studies. Two major strategies have been employed in the gene and miRNA profiling studies: In the first approach, HPV positive tumors were compared to normal tissues or to HPV negative tumors. The second strategy relied on analysis of cell cultures transfected with single HPV oncogenes or with HPV genomes compared to untransfected cells considered as models for the development of premalignant and malignant transformations.

In this review, we summarize what we have learned from a decade of global expression profiling studies. We performed comprehensive analysis of the overlap of the lists of differentially expressed genes and microRNAs, in both tissue samples and cell culture based studies. The review focuses mainly on HPV16, however reports from other HPV species are used as references. We discuss the low degree of consensus among different studies and the limitation of differential expression analysis as well as the fragmented miRNA-mRNA target correlation evidence. Furthermore, we propose an approach for future research to include more comprehensive miRNA-mRNA target correlation analysis and to apply systems biology/gene networks methodology.
\end{abstract}

Keywords: Cervical cancer, head-and-neck cancer, HPV, messenger RNA profiling, miRNA.

\section{INTRODUCTION}

Human papillomaviruses (HPV) were first hypothesized to have oncogenic potential by Harald zur Hausen in 1977 [1] and have subsequently been proven to cause cervical and other genital cancers in both women and men [2]. The importance of HPV in head-and-neck cancers as well as in skin cancers is still a subject of intense debate and as a consequence remains a focus of current research [3-11]. HPV are small viruses with a double-stranded circular DNA genome that encodes seven to eight proteins. Both the structure and function of the virus genomes and viral proteins have been extensively reviewed [12-15].

Among more than 120 sequenced HPV types, approximately 25 types have been demonstrated to be malignant. The prototype HPV16 occurs at the highest prevalence in cervical malignancies and is present, together

*Address correspondence to this author at the Institute of Cellular and Molecular Medicine, DNA Tumour Virus Laboratory, University of Copenhagen, Panum Institute, Blegdamsvej 3, DK-2200 Copenhagen, Denmark; Tel: +45-22262963;

E-mail: bnorrild@sund.ku.dk with HPV18, in approximately 70 percent of genital cancers [2]. The number of HPV-positive head-and-neck cancers varies between 12 and 50 percent in different study populations and in tonsil cancers up to 90 percent are HPVpositive, as recently reviewed by Lajer and von Buchwald [4], Syrjanen et al. [16] and Shaw et al. [8]. The importance of HPV in non-melanoma skin cancer is still under debate and the HPV types involved are different from the malignant HPV types found in squamous carcinomas $[5,17,18]$

The transformation of normal cells by malignant HPV types has been extensively studied and a general concept that HPV oncoproteins E6 and E7 inactivate the guardians of the cell cycle p53 and pRB, creating chromosomal instability has been proposed [19-21]. However, the mechanism of transformation is likely to be more complex. The oncoproteins interact with many more cellular partners than first anticipated and influence a number of cellular pathways [21-25]. Multiple perturbations and accumulation of sequential imprints on cellular function eventually lead to malignant transformation.

Genome-wide technologies have provided the means to study and compare the complex cellular modifications and 
analysis of transcriptomes and proteosomes in normal and transformed cells and tissue. This has paved the way for a better understanding of the complex interactive changes, which occur in a cell during the transformation process. As part of the transcriptome, the small non-coding RNA species (microRNAs, abbreviated miRNAs) have attracted much attention due to both their peculiar processing and their ability to regulate gene expression as reflected in differential expression of certain mRNAs [26]. The present review focuses on mRNA and miRNA profiling data obtained from mainly HPV16-positive cultured cells and HPV-positive cancer specimens. We highlight the possibility of employing global mRNA and miRNA profiling to elucidate the molecular changes during HPV-induced cancer progression.

\section{mRNA PROFILING}

\section{HPV-Positive Cell Lines}

Global profiling of mRNA extracted from cell lines either transfected with HPV16 or isolated from HPVpositive lesions has been valuable for the identification of differentially expressed genes in response to viral gene expression. The questions posed in different studies vary. Profiling has been conducted on primary keratinocytes mainly immortalized with HPV16 - either with E6, E7, E5 or full genomes - or on HPV16-positive cell lines originally established from biopsy specimens. One of the earliest studies showed that differential expression of several cellular transcripts varied dependent on the expression of E7 alone or of E6 plus E7. It also identified several transcripts that were regulated in an opposing manner by E7 alone and E6 plus E7, e.g. vimentin, $p 21$, damage-specific DNA binding protein p48 subunit, Nag-1 and IGFBP6. Other transcripts were potentiated by E6/E7 expression such as Cox-1 [27]. In a more recent study, E7 expression modified IFI44, IFI44L and TP53INP2 - transcripts, which were also found to be downregulated in HPV16-positive HaCaT cells [28, 29]. The annotation of all genes discussed in the manuscript is included as Supplementary Table 1. The annotation includes gene description, function, involvement in biological processes and cellular localization.

Several studies have used cells transfected with the full HPV16 genome, thus allowing analysis of cellular changes related to the gene expression of more viral proteins. As expected, large numbers of transcripts were found to be differentially regulated by the expression of more viral genes. One study focused on the identification of hTERT responsive genes following chromosome 6 fusion into HPV16-immortalized keratinocytes. This led to identification of a different set of differentially expressed genes compared to the E7- and E6/E7-mediated modifications [30]. The study identified 32 candidate genes differentially regulated in response to the expression of hTERT, amongst which a large number of genes involved in signal transduction and cell proliferation. Among the upregulated genes were $I G F 2 B P 1$ and regulators of Gprotein signalling (RGS5) and the WNT pathway (WISP2), whereas the downregulated transcripts included $H C C A 2$ and the DNA damage repair protein $X R C C 1$.

One study explored the effect of TNF-alpha on HPVimmortalized cells and identified KCNK6, PRSS11 and
ANKRD11 as being differentially regulated in HPV16positive cells $[1,31]$. The most recent study where the HPV16 genome was transfected into HaCaT cells identified 338 differentially expressed genes (fold change between -3.8 and 3.5). The most upregulated genes were $A N K R D 1, P S G \mathrm{~s}$ and $H S P B 8$ and among the most downregulated genes were $M M P$ s, SERPINB3 and SERPINB4 [2, 29] (Fig. 1).

Several cell lines have been established from patient biopsy material. The HPV16-positive cell lines W12, CaSki and $\mathrm{SiHa}$ were originally isolated from a low-grade cervical squamous intraepithelial lesion and cervical cancer. W12 cells carry approximately 100 episomal HPV16 genomes [3$11,32]$. SiHa cells have only two genome copies and CaSki cells carry up to 600 genome copies $[12-15,33]$.The W12 cell line has been analysed for differentially regulated transcripts following integration of the HPV genome in late passages and the analysis unveiled 85 differentially expressed genes [2, 34]. The investigators found that the interferon-stimulated transcripts from the genes IFI44, MXI and $M X 2$ were upregulated and several serine proteases as well as HSP70 transcripts were downregulated (Fig. 1). The profiling of SiHa and CaSki RNA identified, among others, differentially regulated transcripts from cell cycle regulatory genes such as MCMs, p16,CDCs, CYCLINs and TOPO2a $[4,35]$. To better understand the global changes caused by HPV in tissue culture cell models, profiling data from cells transfected with malignant or benign virus genomes have been compared [16, 29, 36, 37]. Interestingly, the model in $\mathrm{HaCaT}$ cells revealed upregulation of a series of PSGs and $A N K R D 1$ independent of the HPV type - genes that have not previously been discussed in relation to the life cycle of HPV (Fig. 1).

Other studies have focused on the analysis of differentially regulated transcripts in cell lines grown both as monolayers and as organotypic cultures. The organotypic cultures were found to mimic the cancers better than the monolayer cells $[8,38,39]$.

Not surprisingly, the global profiles obtained in the different studies vary not only because of different experimental models and growth conditions, but also because of the different technologies employed. Although different studies have identified similar differentially expressed genes (IFI44, MXI and CYR61), it has not been possible to reach any consensus based on the model systems described in the present section (see also Fig. 1).

\section{HPV-Positive Tumour Tissues}

\section{Cervical Tissue}

The purpose of cervix cancer (SCC) profiling studies has been to explore genes altered in the progression from benign to malignant growth in order to identify useful biomarkers, important for early diagnosis or prognosis. Furthermore, the identification of affected pathways could give rise to targeted therapy. Messenger RNA profiling studies on cervical cancers have often been conducted with few cases and corresponding control tissues - specimens not always typed for HPV. In studies where the specimens were typed for HPV, the tissues were mainly positive for HPV16 or -18 . However, in the majority of studies, microarray data were 


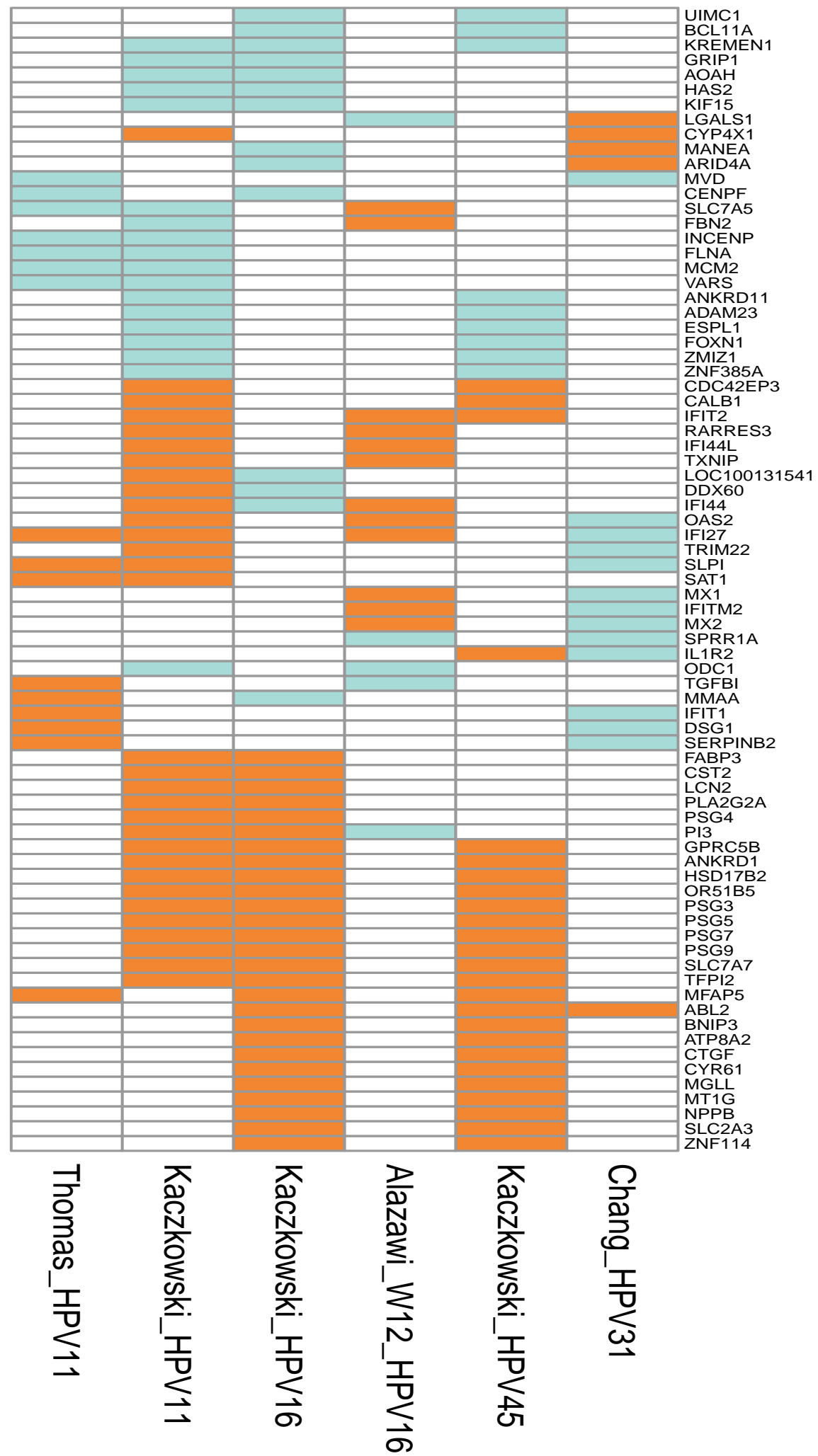

Fig. (1). Graphical representation of the genes that were differentially expressed in at least two cell culture studies. In five of these studies, in vitro cell cultures were transfected with genomes of different HPV types: Thomas HPV11 [37], normal human keratinocytes transfected with HPV11; Kaczkowski_HPV11, Kaczkowski_HPV16 and Kaczkowski_HPV45 [29], HaCaT cells transfected with HPV11, HPV16 and HPV45, respectively; Chang_HPV31 [53], normal human keratinocytes from foreskin tissue transfected with wild type HPV31 genome. W12 was obtained from a low-grade cervical lesion and was naturally infected with HPV16 [34].The upregulated genes are depicted in orange, downregulated in green, and not differentially expressed in white. Interestingly, oncogene $A B L 2$ was found upregulated in high-risk types HPV16, HPV31 and HPV45. The annotations of the genes are included as Supplementary Table 1. 
pooled without taking the specific HPV type into consideration. In the current section, we only review the data from HPV16-positive cancers or from studies where the material did not undergo typing. We have illustrated the common differentially expressed transcripts among various studies (Figs. 2, 3). In the studies where the type has not been reported, the cervical specimens are assumed to be mostly positive for HPV16 which - according to the literature - is most prevalent $(50-60 \%)[2,5,17,18]$. The first HPV study to employ microarray technology was published in 2002 [19-21, 40]. In an attempt to identify markers for the transition from normal or LSIL (low-grade squamous intraepithelial lesion) to HSIL (high-grade squamous intraepithelial lesion) or SCC, a series of 34 cancers was collected, nine of which were SCCs. Profiling of the upregulated transcripts identified 62 genes where ITGB6, $C L D N 1, B S T 2$ and $L A M C 2$ - all surface markers - were characteristic of the pre-malignant to malignant transition [21-25, 41]. However, HPV typing was not performed and the authors excluded immune response genes from the analysis, as the aim of the study was to identify tumour progression biomarkers. In two similar studies where 26 and 10 cancer specimens were analysed, the most differentially expressed genes in the cancers belonged to the cytoskeleton, DNA damage, transcription factors and the Ras oncogene family. Worth noting is the upregulation of casein kinase II (CKII) subunit beta in cancer specimens, as HPV16 E7 can be phosphorylated by CKII [26, 41, 42]. When the focus changed to differentially expressed genes which differed between SCC and CIN3 (HSIL), Sopov et al. [27, 43] identified 92 prominently altered transcripts. Transcripts from 10 cancers and $20 \mathrm{CIN} 3$ specimens revealed genes associated with DNA synthesis (e.g. TOP2), cell adhesion (e.g. $D P$ s), cytokines (e.g. $I F N-\gamma$ ) as well as metabolic pathways (e.g. $A C Y 1$ ). It is still an open question whether these markers can be used for diagnosis and/or prognosis. In a study where the HPV16 E7 mRNA was measured, only three of the eight cancer samples analysed were positive for E7 mRNA [28, 29, 44]. Among the most upregulated transcripts were the keratin mRNAs (e.g. KRT14 and 16), $A U R K B, E I F 4 A 1$ and SPINT2. It is worth noting that this study found differences in the levels of the transcripts among clinical specimens, most likely reflecting the heterogeneity among patients.

A study conducted by Santin et al. [30, 45] described the differentially expressed transcripts obtained from six HPV16-positive SCC specimens and four control samples. The controls were normal cervical tissue specimens from patients with benign genital disease. Primary cell lines were established from all the biopsies and the RNA for mRNA profiling was extracted from these cell cultures grown for a maximum of 15 passages. A large number of differentially regulated genes was identified in the cancer cells and the authors highlighted genes involved in DNA replication, cell cycle progression (e.g. $C D K N 2 A / p 16)$ and the innate immune response to the virus (PTGES) [45]. Downregulated genes belonged to the TNF family of genes, to the inhibitors of serine proteases (SERPINs) and to the keratins - genes repeatedly found to be differentially regulated in HPVpositive tissue culture models too. In another study, Rosty et al. [46] obtained data from 16 primary HPV16-positive
SCCs, five controls and primary cell lines established from invasive SCCs. In this study, a cluster of 163 differentially expressed genes was identified, with the majority involved in cell cycle control, DNA synthesis (e.g. MCMs and POLs), chromosome structure (e.g. $S M C$ s, $H 2 A F X$ and $H 2 A F Z$ ) and molecular trafficking (e.g. $K I F \mathrm{~s}$ ). The so-called 'Rosty cluster' is interesting for two reasons. First, 31 of the genes in the cluster were found to have predictive value for the outcome of breast cancer. Secondly, four of the genes in the cluster (TK1, MYBL2, MCMC4 and TOP2A) were also identified in the study by Chen et al. [41].

A study designed to demonstrate how well cancer cell lines grown in organotropic cultures mimic cancer was conducted by Carlson et al. [38]. The analysis of cancer specimens was performed with nine SCCs and 140 differentially expressed transcripts were identified. Interestingly, the authors compared their findings with pooled data from the literature and found 19 identical transcripts (e.g. TFGBR3, SERPING1, SERPINF1, DSP, $A U R K B)$. The authors also compared the data set of 140 transcripts with the differentially regulated transcripts published by Santin et al. [45]. In this comparison, 11 identical transcripts were found, of which only two (SLC2A1, SERPINF1) were shared by all three of the compared data sets.

\section{Oral and Pharyngeal Tissue}

The results from cervical cancer specimens were regarded as not entirely consistent and to some extent discouraging. However, the increasing interest in HPV as a causal agent in head-and-neck tumours prompted researchers to launch several mRNA profiling studies of head-and-neck cancer specimens. In line with the cervical cancer studies, the aim was to identify biomarkers for cancer development. The prevalence of HPV in tumours from the head-and-neck region is much more variable than in cervical cancer. We therefore focus mainly on studies where the HPV type 16 was identified in the cancer specimens. We have illustrated the transcripts in common among several studies (Figs. 2, 4). One study has reported mRNA profiling of eight HPV16positive head-and-neck squamous cell carcinomas (HNSCCs) (seven isolated from the oropharynx and one from the larynx) and $28 \mathrm{HPV}$-negative tumours where half the specimens were collected from the oral cavity [47]. Ninety-one differentially expressed transcripts were identified and all but two were upregulated and were considered as markers for HPV-positive tumours. The authors identified a cluster of differentially expressed genes located on the chromosomal 3q24-ter region. Examples of genes identified within this chromosomal locus were found to be involved in replication $(R F C 4)$, E2F transcription (TFDP2), chromatin structure (SMARCA3) and apoptosis $(P D C D 10)$. A similar set-up was employed in another study where three HPV16-positive HNSCCs, four HPV-negative HNSCCs and four normal tissue specimens were analysed, leading to the identification of 397 differentially expressed mRNAs in HPV-positive cancers [48]. Among the upregulated genes in the HPV-positive specimens were $C D K N 2 A$ and $M C M \mathrm{~s}$ and a differentiation-related gene SFRP4. The downregulated genes included IGFBP6. The comparison of the mRNA profiles for HPV-positive and 


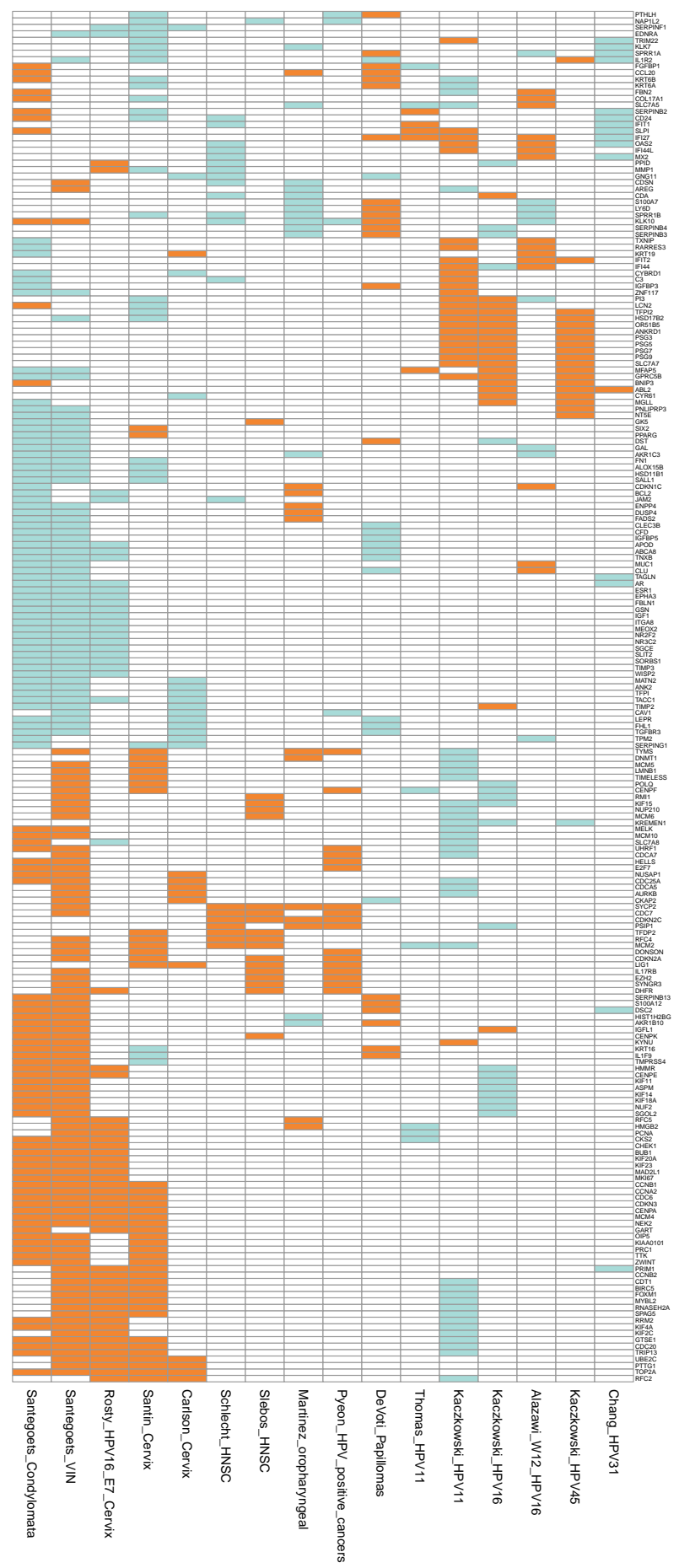

Fig. (2). Graphical representation of the differentially expressed genes from 14 comparisons reported in 12 studies. Genes differentially expressed in at least three comparisons are shown. The comparisons represent genes differentially expressed in benign and malignant growth caused by HPV infection. The signatures represent the differentially expressed genes as follows: Santegoets_Condylomata and Santegoets_VIN [51], condylomata and vulval intraepithelial neoplasia (VIN) versus normal tissue; Rosty_HPV16_E7_Cervix [46], genes correlated to HPV16 E7 expression in cervical cancer; Santin_Cervix [45] and Carlson_Cervix [38], cervical cancer versus normal cervical keratinocytes; Schlecht_HNSC [49] and Slebos_HNSC [47], HPV-positive versus HPV-negative head-and-neck squamous cell carcinoma; Martinez_oropharyngeal [48], HPV-positive versus HPV-negative oropharyngeal squamous cell carcinoma; Pyeon_HPV_positive_cancers [50], HPV-positive head-and-neck cancer (HNC) and cervical cancer versus HPV-negative HNC; DeVoti_Papillomas [52], respiratory papillomas versus adjacent tissue; Thomas_HPV11 [37], normal human keratinocytes transfected with HPV11; Kaczkowski_HPV11, Kaczkowski_HPV16 and Kaczkowski_HPV45 [29], HaCaT cells transfected with HPV11, HPV16 and HPV45, respectively; Alazawi_W12_HPV16 [34], signature from cell line generated from a low-grade cervical lesion naturally infected with HPV16; Chang_HPV31 $[38,53]$, normal human keratinocytes from foreskin tissue transfected with wild type HPV31 genome. The upregulated genes are depicted in orange, downregulated in green, and not differentially expressed in white. The annotations of the genes are included as Supplementary Table $\mathbf{1}$. 


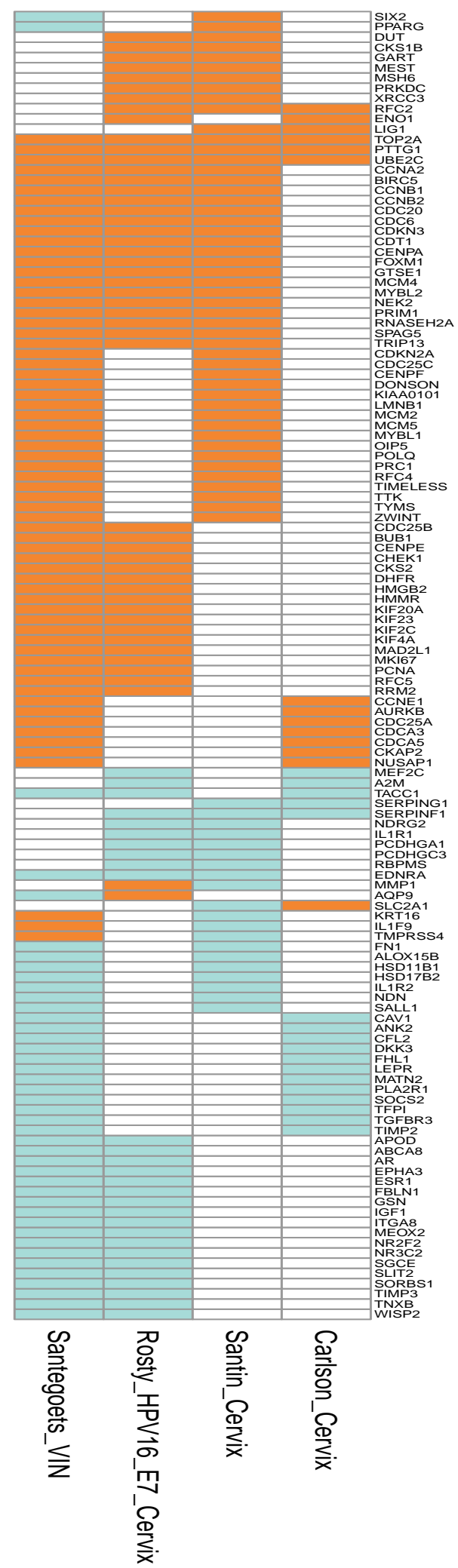

Fig. (3). Depiction of the genes that were differentially expressed in at least two studies based on samples from genital lesions. The signatures represent the differentially expressed genes as follows: Santegoets_VIN [51], vulval intraepithelial neoplasia (VIN) versus normal tissue; Rosty_HPV16_E7_Cervix [46], genes correlated to HPV16 E7 expression in cervical cancer; Santin_Cervix [45] and Carlson_Cervix [38], cervical cancer versus normal cervical keratinocytes. The upregulated genes are depicted in orange, downregulated in green, and not differentially expressed in white. The annotations of the genes are included as Supplementary Table 1. 
HPV-negative cancers also identified interesting differentially expressed transcripts, e.g. BIRC1 and 3, BCL2 and $H L A-D Q A 1 / A 2$ which were upregulated, whereas SERPINB4 was downregulated (Fig. 2). The mRNA profiling study by Schlecht et al. analysed 12 tumours and 30 controls [49]. The biopsies were collected from different sites, with the majority isolated from the oropharynx and the larynx. This study revealed 149 differentially expressed transcripts, of which 123 also belonged to the HPV signature of non-smokers. Among the most upregulated transcripts were $S Y C P 2$ and $C D K N 2 C$. Among the downregulated transcripts, IFI44L should be noted. An even larger study analysed 42 HNSCC specimens, of which only 13 were HPV16-positive [50]. The authors also included eight HPV16-positive cervical SCC specimens. To obtain the HPV signature, they compared the HPV-positive tumours with the HPV-negative tumours. It should be noted that several of the cancer specimens were positive for other HPV types. Since HNSCC and cervical cancer were merged in the analysis, the results provide less information on transcripts specific for HNSCCs. The genes upregulated by HPV were cell cycle genes such as $M C M \mathrm{~s}, C C N B, C D K 2, S Y C P 2$ and $T C A M 1$. It should be noted that the $C D K N 2$ and $S Y C P 2$ genes were upregulated in all the HNSCCs (Fig. 4).

\section{Comparison of mRNA Profiles from HPV16-Positive Tissues}

The mRNA profiles published in one study on vulval intraepithelial neoplasia (VIN), three studies on cervical SCCs, four studies on HNSCCs and six studies on cell lines were combined and the profiling 'landscape' is shown in Fig. (2). Interestingly, there are areas of strong similarity among the signatures from the cervical and vulval lesions, while profiles from HNSCCs show patches of overlap but to a much lesser extent.

Among the cervical and vulval specimens analysed by Rosty et al. [46], Santin et al. [45] and Santegoets et al. [51], the regulated genes are rather consistent. However, the differentially expressed genes published by Carlson et al. [38] show only minor areas of overlap and some of the up- and downregulated genes match mostly genes regulated in the VIN specimens (e.g. upregulated $C D C 25 A, A U R K B$ and $C D C \mathrm{~s}$; downregulated $A N K 2, T I M P 2$ and $T G F B R 3$ ) (Figs. 2, 3, 5A).

The comparison between the HPV6-positive condyloma specimens collected by Santegoets et al. [51] and the HPV6/11-positive laryngeal papillomas studied by DeVoti et al. [52] shows an overlap of 41 transcripts, whereas there is negligible overlap between the results from the HPV11 cell model of Thomas et al. [37] and the two tissue studies (Fig. 5B). This observation emphasizes the difficulties of comparing results obtained from tissue samples and cell culture models.

Assessing the overlap of aberrantly expressed genes in the HNSCC studies, there is a reasonable agreement between the findings of Slebos et al. [47] and Pyeon et al. [50]. Schlecht et al. [49] also observed the upregulation of $C D C 7$, $S Y C P 2$ and $C D K N 2 C$. Among the downregulated genes, $K L K 10$ and $K L K 8$ should be noted. (The genes are listed in Fig. (4). See also Fig. (5C) for overlap between the results from the studies by Schlecht et al. [49], Slebos et al. [47] and Martinez et al. [48].
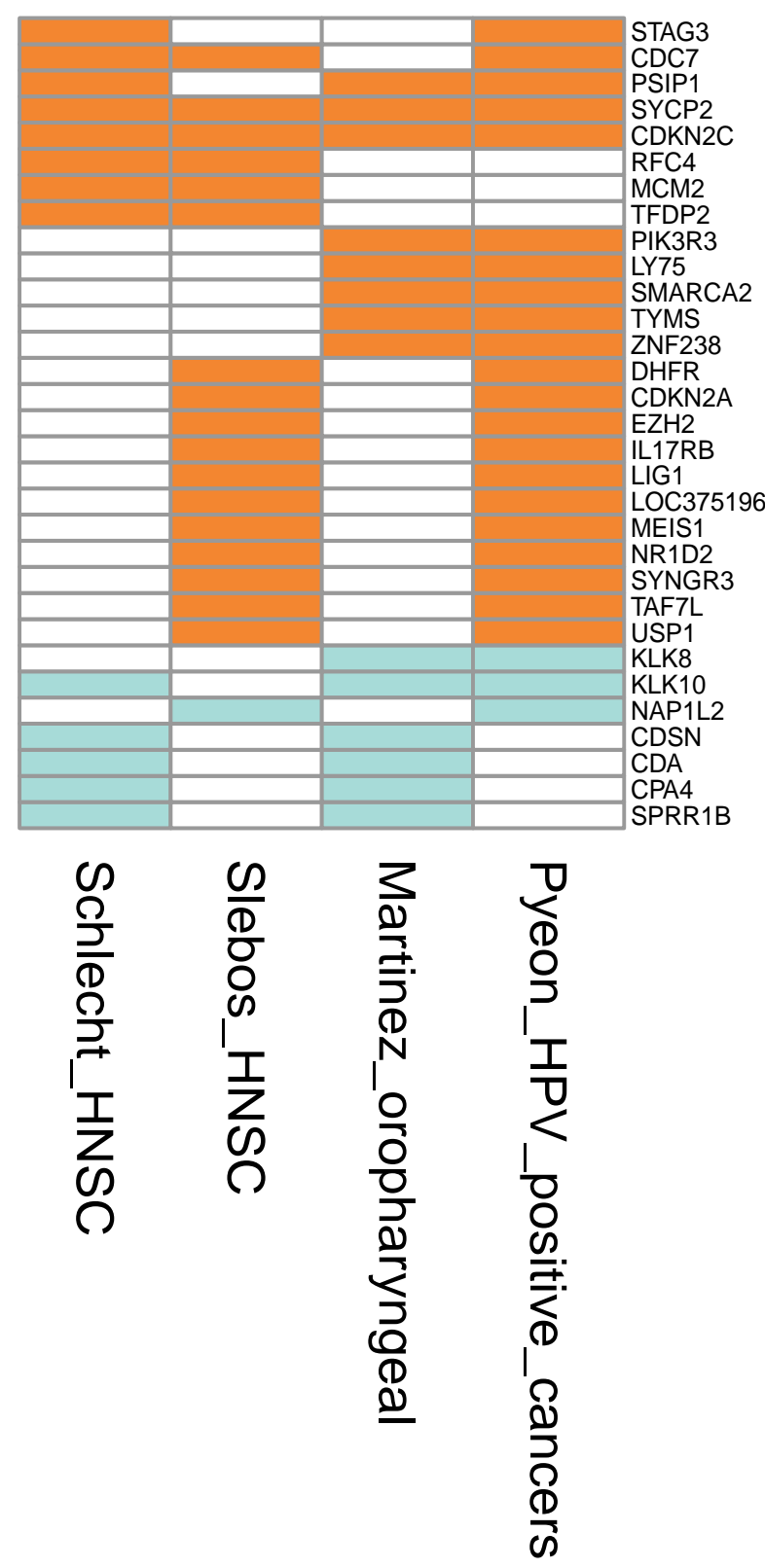

Fig. (4). Graphical representation of the genes that were differentially expressed in at least two studies reporting the differential expression between HPV-positive versus HPV-negative head-and-neck cancers. The signatures represent the differentially expressed genes as follows: Schlecht_HNSC [49] and Slebos_HNSC [47], HPV-positive versus HPV-negative head-andneck squamous cell carcinoma; Martinez_oropharyngeal [48], HPV-positive versus HPV-negative oropharyngeal squamous cell carcinoma; Pyeon_HPV_positive_cancers [50], HPV-positive headand-neck cancer ( $\mathrm{HNC}$ ) and cervical cancer versus HPV-negative HNC. The upregulated genes are depicted in orange, downregulated in green, and not differentially expressed in white. The annotations of the genes are included as Supplementary Table $\mathbf{1 .}$

\section{Comparison of mRNA Profiles from HPV-Positive Cultured Cells}

Cultured HPV-positive cells carrying full genomes of HPV11, HPV16 or HPV31 were compared (Fig. 2). Both 
(A)

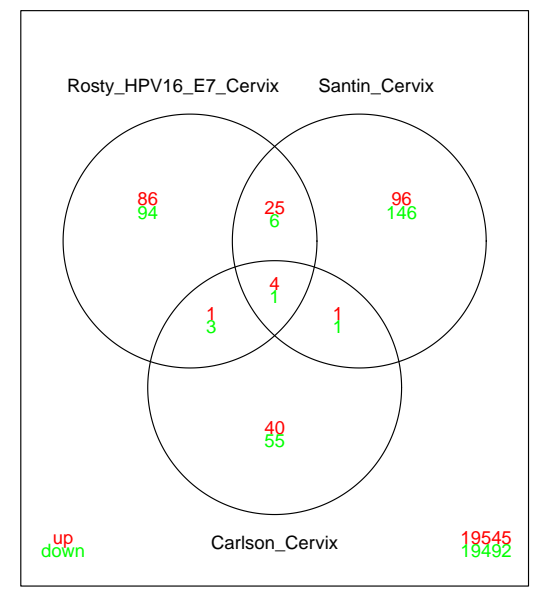

(B)

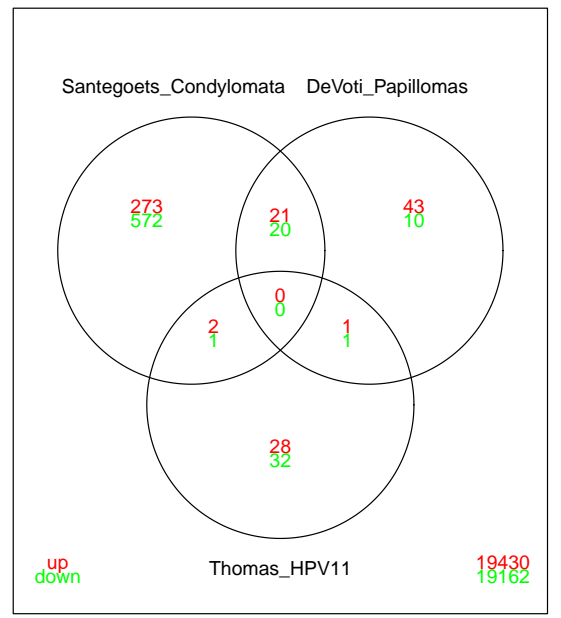

(C)

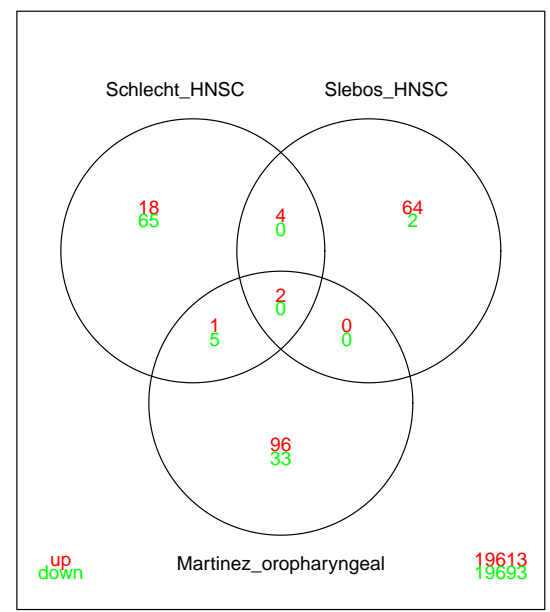

Fig. (5). Venn diagrams illustrating the overlap in differentially expressed genes reported in: A) studies based on cervical cancer tissues. The signatures reported by Rosty et al. [46] and Santin et al. [45, 47] show significant overlap. This is in contrast to the list of genes published by Carlson et al. [38] that shows only negligible overlap with the other studies. The genes present in all three studies are RFC2, TOP2A, PTTG1, UBE2C (upregulated) and SERPINF1 (downregulated) (also seen in Fig. 3). B) Studies of low-risk HPV. Santegoets et al. [51] and DeVoti et al. [52] reported the differentially expressed genes from condyloma and papilloma samples, respectively. Thomas et al. [37] reported the differential expression based on a cell culture model in which normal human keratinocytes were transfected with the HPV11 genome. The Venn diagram demonstrates a notable overlap between the tissue-based studies, especially concerning downregulated genes. However, little overlap can be seen between the tissue-based studies and the HPV11 cell culture model (Thomas_HPV11). C) Studies reporting the differential expression between HPV-positive versus HPV-negative head-and-neck cancers. These studies show very little overlap of the signatures. The two genes upregulated in all the studies are $S Y C P 2$ and $C D K N 2 C$ (also seen in Fig. 4). 
upregulated (SLP1, IFI27, SAT1) and downregulated (SLC7A5, FLNA, VARS, MCM2, INCENP) genes show consistency in the two studies of cell cultures transfected with the circular genome of HPV11, even though Kaczkowski et al. used HaCaT cells [29] and Thomas et al. used human foreskin keratinocytes [37]. The HPV16 and HPV11 cell cultures show overlapping genes to some extent, but also unique HPV type-related transcripts. It should be noted that IFI44 and DDX60 are inversely regulated by the malignant and benign HPV. The IFI44 and PI3 genes are also inversely regulated by the HPV16-positive $\mathrm{HaCaT}$ cells and HPV16-positive W12 cells. Furthermore, these two genes are the only genes in common between the two HPV16 gene profiles (Fig. 1). This might be due to the integration of the virus genome in W12 cells, which were isolated from cancer tissue (Fig. 1). There are very few regulated genes in common between the cell lines carrying the related HPV types 16 and 31 . Only the oncogene $A B L 2$ is upregulated in both cell cultures [29, 37, 53] (Fig. 1). The observed differences in cellular gene profiles revealed by the comparison of different studies are most likely caused by the use of different host cells. The study by Kaczkowski et al. [29] were, as mentioned above, conducted with immortalized skin epithelial cells $(\mathrm{HaCaT})$, whereas the other studies on HPV16-, HPV31- and HPV11-positive cells were performed using human cervical or foreskin epithelial cells. As discussed in a previous section of this review, a series of $P S G$ s as well as $A N K R D I$ were upregulated in $\mathrm{HaCaT}$ cells positive for benign HPV11 or malignant HPV types. Why this is only observed in $\mathrm{HaCaT}$ cells could be a topic for further investigation.

\section{Concensus Among Studies}

Matching of the lists of differentially expressed genes was performed using the official HUGO gene symbols. The matching poses a challenge due to updates and ambiguity of gene names listed in the literature. Additionally, the microarray platforms used in the studies were often based and mapped to older versions of the human genome, and due to a growing body of information concerning the genome, the lists of differentially expressed genes sometimes use outdated gene names. Furthermore, the ID of some probe sets can map to several genes, and since the mapping can be done differently in different studies, the match will not be found by exact matching of gene names. On the other hand, non-exact matching is almost impossible to automate, as it can be very difficult to decide if different gene variants or members of the same gene family represent the same up- or downregulated entity. Therefore, the matching used in this review is very strict. Related genes or gene variants are not presented as a match. This can lead to the bias that results presented by different studies look less coherent than they actually are.

In addition, the statistical analysis of differentially expressed genes is optimized to reduce the number of false positives. This results in strict significance thresholds that many differentially expressed genes do not meet, especially when the number of replicates in the experiment is low. Therefore, only genes showing the strongest differential expression may be detected by multiple or all studies.
The approach that different studies fill the gaps in differential expression analysis can provide a way to balance the number of false positive and false negative genes. For example, we believe that genes reported to be differentially expressed by two independent studies can be safely assumed to be affected in HPV infection or HPV-caused cancers. Therefore, the differential expression in all studies of similar scope should not be considered as a requirement. However, those genes are, of course, of interest due to their very strong signal of differential expression (Fig. 2).

\section{GLOBAL miRNA ANALYSIS}

MicroRNAs are non-coding, endogenous posttranscriptional regulators of gene expression. They are approximately 22 nucleotides in length and are found in a wide range of eukaryotes. Presently, 1, 048 miRNAs have been identified in humans (http://www.mirbase.org) [54]. Several studies have shown that HPV infections result in changes in cellular miRNA profiles. These studies analysed cell lines established from pre-malignant lesions - such as $\mathrm{SiHa}, \mathrm{CaSki}$ and cells from head-and-neck tissue - or model systems. There is also a large amount of information on miRNA profiling of tissue in the literature. The following sections highlight the most interesting recent findings.

\section{HPV-Positive Cell Lines}

For the analysis of miRNA profiles in HPV16-positive cultured cells, the cell lines $\mathrm{SiHa}$ and CaSki have often been employed. We focus on studies where the profiling results are available and related to expression of the HPV oncogenes, with the exclusion of studies designed to analyse the mRNA targets in depth for individual miRNAs as well as studies where the HPV status of the cell lines was not specified.

Martinez et al. conducted a global profiling of miRNAs in cervical cancer-derived $\mathrm{SiHa}$ and CaSki cells and showed that human miR-203 and miR-34a were upregulated and miR-218 was downregulated [55]. However, the regulation of miR-34a has been shown to be inversely regulated in other studies - it was downregulated as a result of the expression of the high-risk E6 oncoprotein and the degradation of $\mathrm{p} 53$, a known regulator of miR-34a transcription [56-58]. In addition, miR-21 was upregulated, as demonstrated in several HPV16-transformed cell lines, whereas miR-143 and miR-145 were downregulated [55, 59, 60] (Table 1).

MicroRNA profiles have also been analysed in HPV16 E5-positive keratinocytes, where miR-146a was found to be upregulated and miR-203 downregulated [61]. The authors of the study proposed suppressor of cytokine signalling-3 (SOCS-3) as the target of miR-203 and its involvement in attenuation of the inflammatory response $[61,62]$. Furthermore, miR-324-5p was constantly repressed in E5expressing cells, whereas its putative target, E-cadherin, was increased at the protein level. These data are interesting as the function of E5 in cell transformation is still not fully understood [63], and one additional mechanism by which HPV16 E5 might contribute to the carcinogenic process in cervical epithelial cells could be controlled by miR-324-5p [61]. 
Table 1. The Most Differentially Expressed or Promoted hsa-miRNAs in Cervical and Head-and-Neck Cancer from Cell Cultures

\begin{tabular}{|c|c|c|c|c|c|}
\hline \multicolumn{6}{|c|}{ Cervical Cancer Cells } \\
\hline & Martinez et al. 2008 [55] & Wang et al. 2008 [60] & Lui et al. 2007 [59] & Greco et al. 2011 [61] & Dreher et al. 2011 [64] \\
\hline miR-200c & up & & & & \\
\hline $\mathrm{miR}-203^{\#}$ & up & & & down & \\
\hline miR-193b & up & & & & \\
\hline miR-34a ${ }^{\#}$ & up & & & & \\
\hline miR-31 & up & & & & \\
\hline miR-210 & up & & & & \\
\hline miR-27a & up & & & & \\
\hline miR-503 & up & & & & \\
\hline miR-27b & up & & & & \\
\hline miR-218 & down & & & & \\
\hline miR-143 ${ }^{\#}$ & down & & down & & \\
\hline miR-145 ${ }^{\#}$ & down & & & & up \\
\hline miR-21 \# & & up & up & & \\
\hline miR-24 & & up & & & \\
\hline miR-27a & & up & & & \\
\hline miR-205 & & up & & & \\
\hline miR-146a ${ }^{\#}$ & & & & up & \\
\hline miR-324-5p & & & & down & \\
\hline miR-125a-5p & & & & & up \\
\hline miR-181c & & & & & up \\
\hline miR-486-5p & & & & & up \\
\hline miR-576-3p ${ }^{\#}$ & & & & & down \\
\hline miR-1293 & & & & & down \\
\hline
\end{tabular}

\section{Head-and-Neck Cancer Cells}

\begin{tabular}{|c|c|}
\hline & Wald et al. 2011 [66] \\
\hline $\operatorname{miR}-363^{\#}$ & up \\
\hline $\operatorname{miR}-497^{\#}$ & up \\
\hline $\operatorname{miR}-33^{\#}$ & up \\
\hline $\operatorname{miR}-155^{\#}$ & down \\
\hline $\operatorname{miR}-181 a^{\#}$ & down \\
\hline miR-181b & down \\
\hline miR-29a & down \\
\hline miR-218 & down \\
\hline miR-222 & down \\
\hline miR-221 & down \\
\hline miR-142-5p & down \\
\hline
\end{tabular}


In a recent study, a model for examining the HPVmediated changes in cellular miRNA profiles was established in HaCaT cells. Cells positive for HPV were analysed and differentially expressed miRNAs shared among the different virus-positive cells were ascertained [64]. In cells positive for HPV16, only three miRNAs unique for HPV16 were regulated - miR-181c and miR-486-5p were upregulated and miR-1293 was downregulated (Table 1). For the present review, it is also of interest to mention that 16 miRNAs were shared with the benign HPV11. Among these, miR-125a-5p was the most upregulated and miR-576-3p was the most downregulated $[64,65]$. Cell lines established from HPV-positive and -negative head-and-neck cancer tissue were also analysed for changes in the miRNA profile [66]. It was found that 11 miRNAs were differentially regulated in HPV-positive HNSCC cells when compared to the profiles obtained from HPV-negative HNSCC cells or normal oral keratinocytes. Three miRNAs were upregulated (miR-363, miR-33 and miR-497) and eight were downregulated, with the two most downregulated being miR-155 and miR-181a (Table 1). The authors of this study did not find miR-21 to be differentially expressed in HPV-positive cell lines, although it was abundant in the cells. The upregulation of miR-363 is interesting because it belongs to the cluster of oncogenic miRNAs, the miR-17-92 family, which might have evolved through a series of mutations [67]. It is therefore likely that miR-363 is involved in dysfunction of the cell cycle, analogous to the function of miR-25 which is also a member of the miR-17-92 family [68]. It is worth noting that miR-155 as well as miR-181a were upregulated in other studies on head-and-neck cells, but the cell lines were not analysed for the presence of HPV [69-71]. The inconsistency among the different studies most likely reflects different HPV status and different origin of the cell cultures.

The profiles of differentially expressed miRNAs observed in raft cultures established from HPV16-positive cells were analysed in a few studies. Raft cultures allow differentiation of the epithelial cells. It was shown that miR$34 \mathrm{a}$ and miR-203 were both downregulated [72, 73]. However, miR-203 is normally upregulated by differentiation of normal human keratinocytes [72]. Supporting results were reported in raft cultures of HPV18 and HPV31 [72, 73].

\section{HPV-Positive Tumour Tissues}

Many studies have focused on the miRNA profiling of tumour tissues with the purpose of identifying unique diagnostic markers for specific cancer types. The hope has also been to find new pathways and mechanisms involved in the progression to cancer and to identify possible drug targets. In cancers related to infection with high-risk HPV, several changes in the miRNA profiles have been observed and the specific findings in cervical tissue and in oralpharyngeal tissue are discussed separately.

\section{Cervical Tissue}

In cervical tissue, miR-21 was most often upregulated, whereas miR-143 and miR-145 were downregulated [26, 60, 74]. (Table 2a), demonstrating that miR-21 could be considered as an oncogene and miR-143 and miR-145 as tumour suppressors. These miRNAs have been reported to be similarly regulated in a wide range of tumours, e.g. glioblastomas [75], B-cell lymphomas [76] and colorectal cancers [77].

Although miR-146a was not differentially expressed in cervical cancer-derived cell lines such as SiHa and CaSki or in HPV-induced pre-neoplastic lesions, it was upregulated in cervical cancer tissues [60]. Among HPV16-derived cancers, miR-146a expression is apparently a specific marker for cervical cancer [60]. Interestingly, other tumour viruses such as Epstein-Barr virus also upregulates miR-146a, perhaps in a NF-kappaB-dependent reaction [78-80]. In contrast to these findings, differential downregulation of miR-146a has been reported in virus-independent cancers, e.g. hormonerefractory prostate cancer [81] and papillary thyroid carcinoma [82].

Other miRNA markers for cervical cancer were reported in a recent study where 102 cervical biopsies were used for predicting and validating the effect of miR-200a and miR-9 for cancer development [83]. The study predicted gene targets for miR-200a to regulate mainly cell migration and metastasis and target genes for miR-9 to regulate mainly cell metabolism. The two miRNAs were also found to have prognostic value for prediction of patient survival. The authors of the study also reported that miR-21 was upregulated and that miR-218 and miR-203 were downregulated. These findings have been reproduced in subsequent studies [84, 85].

\section{Oral and Pharyngeal Tissue}

MicroRNA profiling of oral-pharyngeal cancer tissue has been studied in a large number of both HPV-positive and HPV-negative tumours. The involvement of miRNAs in head-and-neck tumours has been reviewed by other groups in 2009 and 2010 [86-88]. However, the studies discussed by the authors of these reviews did not consider the influence of HPV. Recent studies conducted in collaboration with our group revealed the differential regulation of 114 miRNAs in OSCC (oral squamous cell carcinoma) and 38 differentially expressed miRNAs in PSCC (pharyngeal squamous cell carcinoma) [89]. In these studies, the cancer material was carefully sorted in relation to anatomic site and analysed for HPV-positive and -negative tumours. The studies demonstrated that miRNA profiling is characteristic for each tumour category and that the HPV-positive tumours group as a specific disease. The most differentially upregulated miRNA in OSCC was miR-31 and the most downregulated was miR-375, in line with the findings of Li et al. [84]. In HPV-positive PSCC, the most upregulated miRNA was miR-363, in accordance with the observations of Wald et al. in cultured head-and-neck cells [66], and the most downregulated was miR-127-3p (Table 2b). Interestingly, both miR-143 and miR-145 were two-fold downregulated, similar to the findings reported for cervical cancer specimens [60]. Analysis of laser-captured tissue from HPV-positive versus -negative TSCC (tonsil squamous cell carcinoma) identified a set of 36 differentially expressed miRNAs. It is worth noting the absence of miR-143 and miR-145 from this set, which corresponds to the findings discussed in the previous section regarding the consistent downregulation of these two miRNAs in a wide range of tumours. The most differentially expressed miRNAs in the TSCC specimens were miR-363, miR-21 (upregulated) and miR-193b* (downregulated) [90] (Table 2b). This study also addressed a 
Table 2a. The Most Differentially Expressed or Promoted hsa-miRNAs in Cervical Cancer from Tissues

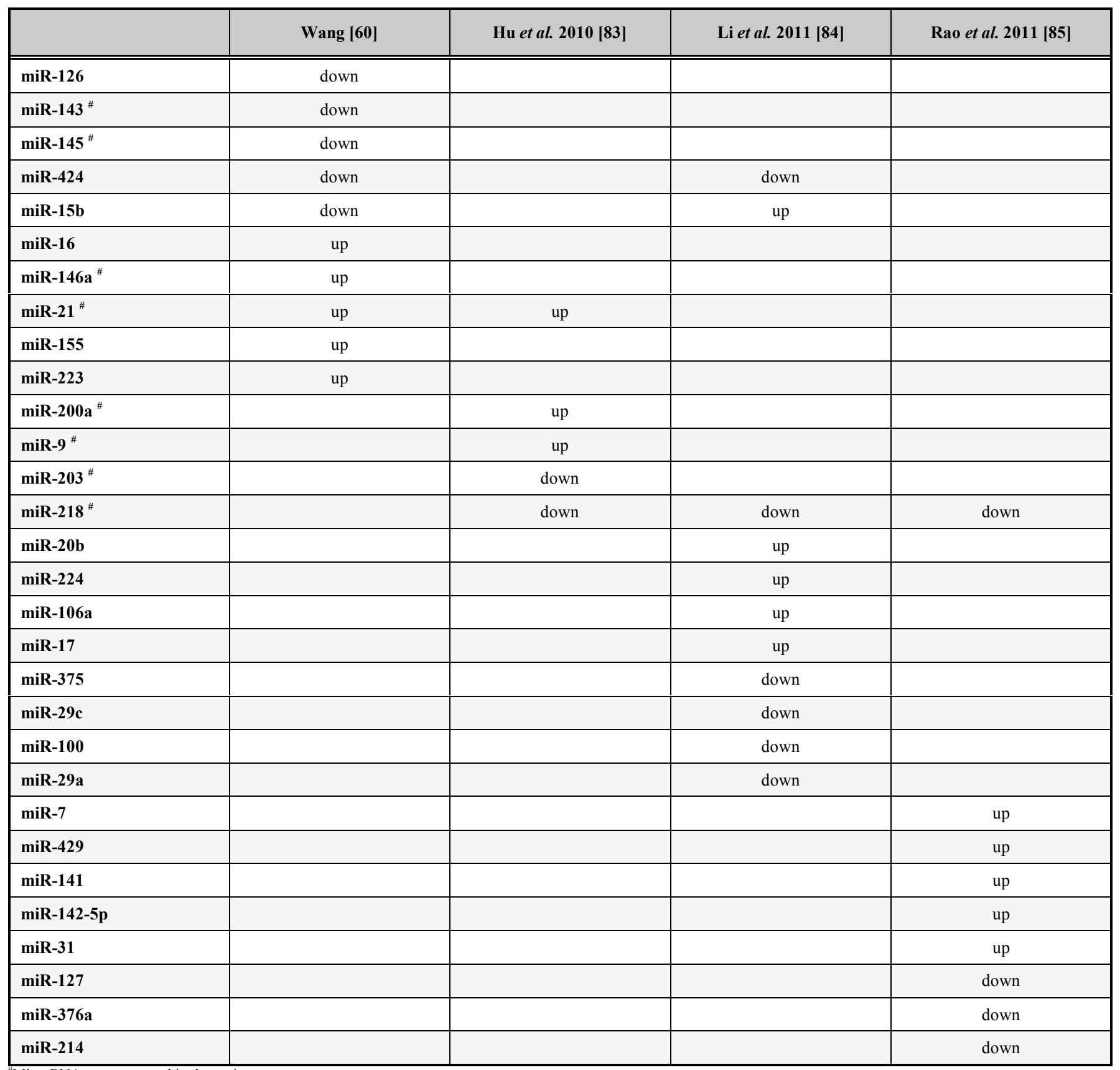

${ }^{\#}$ MicroRNAs are presented in the review.

comparison of miRNA profiling in HNSCC and in cervical squamous cell carcinoma (CSCC) specimens, where a core set of 14 miRNAs was shared among HPV-positive HNSCC and CSCC samples. Interestingly, miR-145 was a member of this core set.

\section{PERSPECTIVES}

\section{mRNA and miRNA Correlations}

Extensive expression profiling studies have been performed for both mRNAs and miRNAs. However, little is known concerning the regulatory dependencies between miRNAs and their mRNA targets in HPV infections and HPV-caused cancers. Unveiling of the regulation is hampered by the fact that a single miRNA can target multiple mRNAs and a single mRNA can be targeted by multiple miRNAs. Additionally, miRNAs function as finetuners or modulators rather than binary switches of gene expression.

In the cited studies of this review, there is a large number of changes in mRNA expression that are not due to miRNA regulation, e.g. the activity of viral proteins on cellular transcription factors and signalling pathways. In addition, multiple miRNAs are affected during HPV infection, many of them having multiple mRNA targets. Finally, the causality is difficult to establish. First, miRNAs can be induced by viral activity. Secondly, there can be a cellular response to the changes caused by the virus. 
Table 2b. The Most Differentially Expressed or Promoted hsa-miRNAs in Head-and-Neck Cancer from Tissues

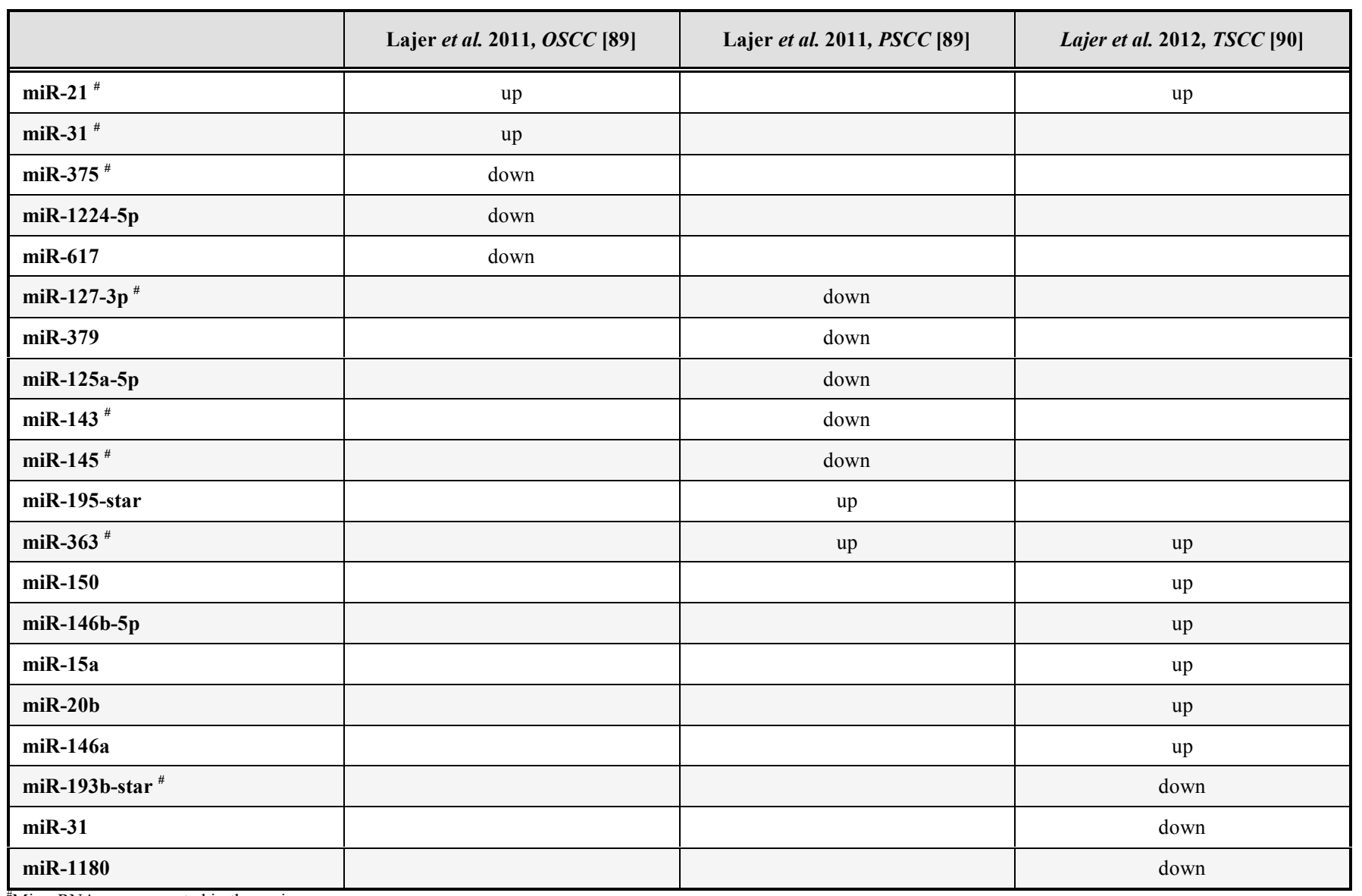

${ }^{*}$ MicroRNAs are presented in the review.

The array studies published to date for HPV have addressed the regulation between miRNAs and mRNAs on a one-to-one basis only $[56,75,91]$. In order to elucidate the regulatory dependencies in these complex settings, one needs a substantial number of paired expression profiles of miRNAs and mRNAs and an extensive computational analysis. Such an analysis has been reported for hepatitis $\mathrm{C}$ virus [92]. However, no studies of this type have presently been employed in relation to HPV infections. Such studies could further add to the understanding of the importance of miRNA targeting as a regulatory tool used by the virus to modulate the host cell gene expression to the benefit of the virus.

\section{Network Approach}

The variation observed in different studies appearing to use similar experimental or clinical conditions should be considered with caution. First, single genes have multiple functions and can be involved in many pathways and cellular processes. If one finds that a HPV type leads to differentially expressed genes which turn out to be similar to those found in another study, this does not guarantee that the same pathway or cellular process is affected by the HPV type in both studies.

Secondly, different HPV types in different biological conditions can affect the same pathway, but by affecting different genes in the cascade of genes involved. Therefore, different genes observed to be differentially expressed might influence the same pathway.

We believe that future comparisons of the outcomes of different studies should be carried out on the level of affected pathways and cellular processes rather than by comparing lists of differentially expressed genes. Standard differential expression analysis does not provide the answers to which pathways and cellular processes are affected. Additionally, long lists of genes are very difficult for the reader to comprehend.

Often, arbitrary sets of genes are randomly selected from a long list of data and interpreted as the biological findings while the remainder of the genes on the list are ignored. Hence, in our opinion, more advanced bioinformatic analysis is required to overcome the limitations of such an approach. In our recent study, we integrated available knowledge of protein-protein interactions, molecular signatures, cellular pathways and transcription factor binding sites [29]. The outcomes of such analyses add more information to which pathways and networks of genes are affected by the virus. The results are therefore more informative to the reader and make the comparison of different studies easier. We believe that such an approach can facilitate significant biological findings and an understanding of the biology behind the observed differential expression. 


\section{CONFLICT OF INTEREST}

The authors confirm that this article content has no conflict of interest.

\section{ACKNOWLEDGEMENTS}

Declared none.

\section{SUPPLEMENTARY MATERIAL}

Supplementary material is available on the publisher's web site along with the published article.

\section{REFERENCES}

[1] Hausen zur H. Human papillomaviruses and their possible role in squamous cell carcinomas. Curr Top Microbiol Immunol 1977; 78: 1-30.

[2] Bosch FX, Burchell AN, Schiffman M, et al. Epidemiology and natural history of human papillomavirus infections and typespecific implications in cervical neoplasia. Vaccine 2008; 26 (Suppl 10): K1-16.

[3] Du J, Nasman A, Carlson JW, Ramqvist T, Dalianis T. Prevalence of human papillomavirus (HPV) types in cervical cancer 20032008 in Stockholm, Sweden, before public HPV vaccination. Acta Oncol 2011;50 (8): 1215-9.

[4] Lajer CB, von BC. The role of human papillomavirus in head and neck cancer. APMIS 2010; 118(6-7): 510-9.

[5] Forslund O, Lindelöf B, Hradil E, et al. High prevalence of cutaneous human papillomavirus DNA on the top of skin tumors but not in "Stripped" biopsies from the same tumors. J Invest Dermatol 2004; 123(2): 388-94

[6] Masini C, Fuchs PG, Gabrielli F, et al. Evidence for the association of human papillomavirus infection and cutaneous squamous cell carcinoma in immunocompetent individuals. Arch Dermatol 2003; 139(7): 890-4

[7] Ramqvist T, Dalianis T. An epidemic of oropharyngeal squamous cell carcinoma (OSCC) due to human papillomavirus (HPV) infection and aspects of treatment and prevention. Anticancer Res 2011; 31(5): 1515-9.

[8] Shaw R, Robinson M. The increasing clinical relevance of human papillomavirus type 16 (HPV-16) infection in oropharyngeal cancer. Br J Oral Maxillofac Surg 2011; 49(6): 423-9.

[9] Smith EM, Rubenstein LM, Hoffman H, Haugen TH, Turek LP. Human papillomavirus, p16 and p53 expression associated with survival of head and neck cancer. Infect Agent Cancer 2010; 5: 4.

[10] Syrjanen S. Human papillomaviruses in head and neck carcinomas. N Engl J Med 2007; 356(19): 1993-5.

[11] van Houten VM, Snijders PJ, van den Brekel MW, Kummer JA, Meijer CJ, van LB, et al. Biological evidence that human papillomaviruses are etiologically involved in a subgroup of head and neck squamous cell carcinomas. Int J Cancer 2001; 93(2): 2325.

[12] Chow LT, Broker TR, Steinberg BM. The natural history of human papillomavirus infections of the mucosal epithelia. APMIS 2010; 118(6-7): 422-49.

[13] Ghittoni R, Accardi R, Hasan U, Gheit T, Sylla B, Tommasino M. The biological properties of E6 and E7 oncoproteins from human papillomaviruses. Virus Genes 2010; 40 (1): 1-13.

[14] Hebner CM, Laimins LA. Human papillomaviruses: basic mechanisms of pathogenesis and oncogenicity. Rev Med Virol 2006; 16(2): 83-97.

[15] Munger K, Basile JR, Duensing S, et al. Biological activities and molecular targets of the human papillomavirus E7 oncoprotein. Oncogene 2001; 20(54): 7888.-98.

[16] Syrjanen S, Lodi G, I von B, et al. Human papillomaviruses in oral carcinoma and oral potentially malignant disorders: a systematic review. Oral Dis 2011; 17(Suppl 1): 58-72.

[17] Dell'Oste V, Azzimonti B, De AM, et al. High beta-HPV DNA loads and strong seroreactivity are present in epidermodysplasia verruciformis. J Invest Dermatol 2009; 129(4): 1026-34.

[18] Massimi P, Thomas M, Bouvard V, et al. Comparative transforming potential of different human papillomaviruses associated with non-melanoma skin cancer. Virol 2008; 371(2): 374-9.
[19] Duensing S, Munger K. Centrosome abnormalities and genomic instability induced by human papillomavirus oncoproteins. Prog Cell Cycle Res 2003; 5 : 383-91.

[20] Farthing AJ, Vousden KH. Functions of human papillomavirus E6 and E7 oncoproteins. Trends Microbiol 1994; 2(5): 170-4.

[21] Thomas M, Pim D, Banks L. The role of the E6-p53 interaction in the molecular pathogenesis of HPV. Oncogene 1999; 18(53): 7690700 .

[22] Moody CA, Laimins LA. Human papillomavirus oncoproteins: pathways to transformation. Nat Rev Cancer Nat Pub Group 2010; 10(8): 550-60.

[23] Pim D, Banks L. Interaction of viral oncoproteins with cellular target molecules: infection with high-risk vs low-risk human papillomaviruses. APMIS 2010; 118(6-7): 471-93.

[24] Thomas M, Massimi P, Navarro C, Borg JP, Banks L. The $\mathrm{hScrib} / \mathrm{Dlg}$ apico-basal control complex is differentially targeted by HPV-16 and HPV-18 E6 proteins. Oncogene 2005; 24(41): 622230.

[25] Yim EK, Park JS. The role of HPV E6 and E7 oncoproteins in HPV-associated cervical carcinogenesis. Cancer Res Treat 2005; 37(6): 319-24.

[26] Zheng ZM, Wang X. Regulation of cellular miRNA expression by human papillomaviruses. Biochim Biophys Acta 2011; 1809(1112): 668-77.

[27] Duffy CL, Phillips SL, Klingelhutz AJ. Microarray analysis identifies differentiation-associated genes regulated by human papillomavirus type 16 E6. Virol 2003; 314(1): 196-205.

[28] Boccardo E, Manzini Baldi CV, Carvalho AF, et al. Expression of human papillomavirus type 16 E7 oncoprotein alters keratinocytes expression profile in response to tumor necrosis factor. Carcinogen 2010; 31(3): 521-31

[29] Kaczkowski B, Rossing M, Andersen DK, et al. Integrative analyses reveal novel strategies in HPV11,-16 and -45 early infection. Sci Rep [Internet]. Nat Pub Group 2012; 2: 515. Available from: http://eutils.ncbi.nlm.nih.gov/entrez/eutils/elink.fc gi dbfrom $=$ pubmed $\&$ id $=22808421 \&$ retmode $=$ ref $\& \mathrm{cmd}=$ prlinks

[30] de Wilde J, Wilting SM, Meijer CJ, et al. Gene expression profiling to identify markers associated with deregulated hTERT in HPVtransformed keratinocytes and cervical cancer. Int J Cancer 2008; 122(4): 877-88.

[31] Termini L, Boccardo E, Esteves GH, et al. Characterization of global transcription profile of normal and HPV-immortalized keratinocytes and their response to TNF treatment. BMC Med Genom 2008; 1: 29.

[32] Stanley MA, Browne HM, Appleby M, Minson AC. Properties of a non-tumorigenic human cervical keratinocyte cell line. Int J Cancer 1989; 43(4): 672-6.

[33] Baker CC, Phelps WC, Lindgren V, Braun MJ, Gonda MA, Howley PM. Structural and transcriptional analysis of human papillomavirus type 16 sequences in cervical carcinoma cell lines. J Virol 1987; 61(4): 962-71.

[34] Alazawi W, Pett M, Arch B, et al. Changes in cervical keratinocyte gene expression associated with integration of human papillomavirus 16. Cancer Res 2002; 62(23): 6959-65.

[35] Martin CM, Astbury K, McEvoy L, O'Toole S, Sheils O, O'Leary JJ. Gene expression profiling in cervical cancer: identification of novel markers for disease diagnosis and therapy. Meth Mol Biol 2009; 511: 333-59.

[36] Chang YE, Laimins LA. Interferon-inducible genes are major targets of human papillomavirus type 31: insights from microarray analysis. Dis Mark 2001; 17(3): 139-42.

[37] Thomas JT, Oh ST, Terhune SS, Laimins LA. Cellular changes induced by low-risk human papillomavirus type 11 in keratinocyte that stably maintain viral episomes. J Virol 2001; 75(16): 7564-71.

[38] Carlson MW, Iyer VR, Marcotte EM. Quantitative gene expression assessment identifies appropriate cell line models for individual cervical cancer pathways. BMC Genom Bio Med Central Ltd 2007; 8(1): 117.

[39] Garner-Hamrick PA, Fostel JM, Chien W-M, et al. Global effects of human papillomavirus type $18 \mathrm{E} 6 / \mathrm{E} 7$ in an organotypic keratinocyte culture system. J Virol 2004; 78(17): 9041-50.

[40] Cheng Q, Lau WM, Tay SK, Chew SH, Ho TH, Hui KM. Identification and characterization of genes involved in the carcinogenesis of human squamous cell cervical carcinoma. Int $\mathrm{J}$ Cancer 2002; 98(3): 419-26. 
[41] Chen Y, Miller C, Mosher R, et al. Identification of cervical cancer markers by cDNA and tissue microarrays. Cancer Res 2003; 63(8): 1927-35.

[42] Wong YF, Selvanayagam ZE, Wei N, et al. Expression genomics of cervical cancer: molecular classification and prediction of radiotherapy response by DNA microarray. Clin Cancer Res 2003; 9(15): 5486-92.

[43] Sopov I, Sorensen T, Magbagbeolu M, et al. Detection of cancerrelated gene expression profiles in severe cervical neoplasia. Int $\mathbf{J}$ Cancer 2004; 112(1): 33-43.

[44] Sgarlato GD, Eastman CL, Sussman HH. Panel of genes transcriptionally up-regulated in squamous cell carcinoma of the cervix identified by representational difference analysis, confirmed by macroarray, and validated by real-time quantitative reverse transcription-PCR. Clin Chem 2005; 51(1): 27-34.

[45] Santin AD, Zhan F, Bignotti E, et al. Gene expression profiles of primary HPV16- and HPV18-infected early stage cervical cancers and normal cervical epithelium: identification of novel candidate molecular markers for cervical cancer diagnosis and therapy. Virol 2005; 331(2): 269-91.

[46] Rosty C, Sheffer M, Tsafrir D, et al. Identification of a proliferation gene cluster associated with HPV E6/E7 expression level and viral DNA load in invasive cervical carcinoma. Oncogene 2005; 24(47): 7094-104.

[47] Slebos RJC, Yi Y, Ely K, et al. Gene expression differences associated with human papillomavirus status in head and neck squamous cell carcinoma. Clin Cancer Res 2006; 12 (3 Pt 1): 701-9.

[48] Martinez I, Wang J, Hobson KF, Ferris RL, Khan SA. Identification of differentially expressed genes in HPV-positive and HPV-negative oropharyngeal squamous cell carcinomas. Eur $\mathrm{J}$ Cancer 2007; 43(2): 415-32.

[49] Schlecht NF, Burk RD, Adrien L, et al. Gene expression profiles in HPV-infected head and neck cancer. J Pathol 2007; 213(3): 283-93.

[50] Pyeon D, Newton MA, Lambert PF, et al. Fundamental Differences in Cell Cycle Deregulation in Human Papillomavirus-Positive and Human Papillomavirus-Negative Head/Neck and Cervical Cancers. Cancer Res 2007; 67(10): 4605-19.

[51] Santegoets LAM, van Baars R, Terlou A, et al. Different DNA damage and cell cycle checkpoint control in low- and high-risk human papillomavirus infections of the vulva. Int J Cancer 2012; 130(12): 2874-85.

[52] DeVoti JA, Rosenthal DW, Wu R, Abramson AL, STEINBERG $\mathrm{BM}$, Bonagura VR. Immune dysregulation and tumor-associated gene changes in recurrent respiratory papillomatosis: a paired microarray analysis. Mol Med 2008; 14(9-10): 608-17.

[53] Chang YE, Laimins LA. Microarray analysis identifies interferoninducible genes and Stat-1 as major transcriptional targets of human papillomavirus type 31. J Virol 2000; 74(9): 4174-82.

[54] Lee RC, Feinbaum RL, Ambros V. The C. elegans heterochronic gene lin-4 encodes small RNAs with antisense complementarity to lin-14. Cell 1993; 75(5): 843-54.

[55] Martinez I, Gardiner AS, Board KF, Monzon FA, Edwards RP, Khan SA. Human papillomavirus type 16 reduces the expression of microRNA-218 in cervical carcinoma cells. Oncogene 2008; 27(18): 2575-82.

[56] Chang TC, Wentzel EA, Kent OA, et al. Transactivation of miR$34 \mathrm{a}$ by $\mathrm{p} 53$ broadly influences gene expression and promotes apoptosis. Mol Cell 2007; 26(5): 745-52.

[57] He L, He X, Lim LP, et al. A microRNA component of the p53 tumour suppressor network. Nature 2007; 447(7148): 1130-4.

[58] Raver-Shapira N, Marciano E, Meiri E, et al. Transcriptional activation of miR-34a contributes to p53-mediated apoptosis. Mol Cell 2007; 26(5): 731-43.

[59] Lui WO, Pourmand N, Patterson BK, Fire A. Patterns of known and novel small RNAs in human cervical cancer. Cancer Res 2007; 67(13): 6031-43.

[60] Wang X, Tang S, Le S-Y, et al. Aberrant expression of oncogenic and tumor-suppressive microRNAs in cervical cancer is required for cancer cell growth. PLoS One 2008; 3(7): e2557.

[61] Greco D, Kivi N, Qian K, Leivonen SK, Auvinen P, Auvinen E. Human papillomavirus 16 E5 modulates the expression of host microRNAs. PLoS One 2011; 6(7): e21646.

[62] Sonkoly E, Wei T, Janson PC, et al. MicroRNAs: novel regulators involved in the pathogenesis of psoriasis? PLoS One 2007; 2(7): e610.
[63] Crusius K, Rodriguez I, Alonso A. The human papillomavirus type 16 E5 protein modulates ERK1/2 and p38 MAP kinase activation by an EGFR-Independent process in stressed human keratinocytes. Virus Genes 2000; 20(1): 65-9.

[64] Dreher A, Rossing M, Kaczkowski B, et al. Differential expression of cellular microRNAs in HPV 11, -16 , and -45 transfected cells. Biochemical and Biophysical Research Communications [Internet]. Elsevier Inc; 2011; 412(1): 20-5. Available from: http://eutils. ncbi.nlm.nih.gov/entrez/eutils/elink.fcgi?dbfrom=pubmed\&id=2178 2796\& retmode $=$ ref\&cmd $=$ prlinks

[65] Dreher A, Rossing M, Kaczkowski B, Nielsen FC, Norrild B Differential expression of cellular microRNAs in HPV-11 transfected cells. An analysis by three different array platforms and qRT-PCR. Biochemical and Biophysical Research Communications [Internet]. Elsevier Inc 2010; 403(3-4): 357-62. Available from: http://eutils.ncbi.nlm.nih.gov/entrez/eutils/elink.fcgi?dbfrom $=$ pubmed\&id $=21078297 \&$ retmode $=$ ref $\& \mathrm{cmd}=$ prlinks

[66] Wald AI, Hoskins EE, Wells SI, Ferris RL, Khan SA. Alteration of microRNA profiles in squamous cell carcinoma of the head and neck cell lines by human papillomavirus. Head Neck 2011; 33(4): 504-12.

[67] Ventura A, Young AG, Winslow MM, et al. Targeted deletion reveals essential and overlapping functionZs of the miR-17 through 92 family of miRNA clusters. Cell 2008; 132(5): 875-86.

[68] Kim YK, Yu J, Han TS, et al. Functional links between clustered microRNAs: suppression of cell-cycle inhibitors by microRNA clusters in gastric cancer. Nucleic Acids Res 2009; 37(5): 1672-81.

[69] Chang SS, Jiang WW, Smith I, et al. MicroRNA alterations in head and neck squamous cell carcinoma. Int J Cancer 2008; 123(12): 2791-7.

[70] Wong TS, Liu XB, Chung-Wai HA, Po-Wing YA, Wai-Man NR, Ignace WW. Identification of pyruvate kinase type M2 as potential oncoprotein in squamous cell carcinoma of tongue through microRNA profiling. Int J Cancer 2008; 123(2): 251-7.

[71] Wong TS, Liu XB, Wong BY, Ng RW, Yuen AP, Wei WI. Mature miR-184 as Potential Oncogenic microRNA of Squamous Cell Carcinoma of Tongue. Clin Cancer Res 2008; 14(9): 2588-92.

[72] Melar-New M, Laimins LA. Human papillomaviruses modulate expression of microRNA 203 upon epithelial differentiation to control levels of p63 proteins. J Virol 2010; 84(10): 5212-21.

[73] Wang X, Wang HK, McCoy JP, et al. Oncogenic HPV infection interrupts the expression of tumor-suppressive miR-34a through viral oncoprotein E6. RNA 2009; 15(4): 637-47.

[74] Pereira PM, Marques JP, Soares AR, Carreto L, Santos MAS. MicroRNA expression variability in human cervical tissues. PLoS One 2010; 5(7): e11780.

[75] Chan JA, Krichevsky AM, Kosik KS. MicroRNA-21 is an antiapoptotic factor in human glioblastoma cells. Cancer Res 2005; 65(14): 6029-33.

[76] Akao Y, Nakagawa Y, Kitade Y, Kinoshita T, Naoe T. Downregulation of microRNAs-143 and -145 in B-cell malignancies. Cancer Sci 2007; 98(12): 1914-20.

[77] Slaby O, Svoboda M, Fabian P, et al. Altered expression of miR21, miR-31, miR-143 and miR-145 is related to clinicopathologic features of colorectal cancer. Oncol 2007; 72(5-6): 397-402.

[78] Cameron JE, Yin Q, Fewell C, et al. Epstein-Barr virus latent membrane protein 1 induces cellular MicroRNA miR-146a, a modulator of lymphocyte signaling pathways. J Virol 2008; 82(4): 1946-58.

[79] Motsch N, Pfuhl T, Mrazek J, Barth S, Grasser FA. Epstein-Barr virus-encoded latent membrane protein 1 (LMP1) induces the expression of the cellular microRNA miR-146a. RNA Biol 2007; 4(3): 131-7.

[80] Taganov KD, Boldin MP, Chang KJ, Baltimore D. NF-kappaBdependent induction of microRNA miR-146, an inhibitor targeted to signaling proteins of innate immune responses. Proc Natl Acad Sci USA 2006; 103(33): 12481-6.

[81] Lin SL, Chiang A, Chang D, Ying SY. Loss of mir-146a function in hormone-refractory prostate cancer. RNA 2008; 14(3): 417-24.

[82] He H, Jazdzewski K, Li W, et al. The role of microRNA genes in papillary thyroid carcinoma. Proc Natl Acad Sci USA 2005; 102(52): 19075-80.

[83] Hu X, Schwarz JK, Lewis JS Jr, et al. A microRNA expression signature for cervical cancer prognosis. Cancer Res 2010; 70(4): 1441-8. 
[84] Li Y, Wang F, Xu J, et al. Progressive miRNA expression profiles in cervical carcinogenesis and identification of HPV-related target genes for miR-29. J Pathol 2011; 224(4): 484-95.

[85] Rao Q, Zhou H, Peng Y, Li J, Lin Z. Aberrant microRNA expression in human cervical carcinomas. Med Oncol 2012; 29(2): $1242-8$.

[86] Chen LH, Tsai KL, Chen YW, et al. MicroRNA as a Novel Modulator in Head and Neck Squamous Carcinoma. J Oncol 2010; 135632.

[87] Liu X, Chen Z, Yu J, Xia J, Zhou X. MicroRNA profiling and head and neck cancer. Comp Funct Genomics 2009; 837514.

[88] Tran N, O'Brien CJ, Clark J, Rose B. Potential role of micro-RNAs in head and neck tumorigenesis. Head Neck 2010; 32(8): 1099-111.
[89] Lajer CB, Nielsen FC, Friis-Hansen L, et al. Different miRNA signatures of oral and pharyngeal squamous cell carcinomas: a prospective translational study. Br J Cancer 2011; 104(5): 830-40.

[90] Lajer CB, Garnaes E, Friis-Hansen L, et al. The role of miRNAs in human papilloma virus (HPV)-associated cancers: bridging between HPV-related head and neck cancer and cervical cancer. $\mathrm{Br}$ J Cancer 2012; 106(9): 1526-34.

[91] Martin MM, Lee EJ, Buckenberger JA, Schmittgen TD, Elton TS. MicroRNA-155 regulates human angiotensin II type 1 receptor expression in fibroblasts. J Biol Chem 2006; 281(27): 18277-84.

[92] Peng X, Li Y, Walters K-A, et al. Computational identification of hepatitis $\mathrm{C}$ virus associated microRNA-mRNA regulatory modules in human livers. BMC Genomics 2009; 10: 373

(C) Kaczkowski et al.; Licensee Bentham Open.

This is an open access article licensed under the terms of the Creative Commons Attribution Non-Commercial License (http: //creativecommons.org/licenses/by$\mathrm{nc} / 3.0 /$ ) which permits unrestricted, non-commercial use, distribution and reproduction in any medium, provided the work is properly cited. 